\title{
NINCDS-ADRDA Criteria for Alzheimer's Disease
}

National Cancer Institute

\section{Source}

National Cancer Institute. NINCDS-ADRDA Criteria for Alzheimer's Disease. NCI

Thesaurus. Code C86983.

Criteria for the diagnosis of Alzheimer's disease (AD), proposed in 1984 by the National Institute of Neurological and Communicative Disorders (NINCDS) and the StrokeAlzheimer's Disease and Related Disorders Association (ADRDA, now the Alzheimer's Association). The criteria state that existing cognitive impairment may be considered possible or probable AD by neuropsychological testing but definitive diagnosis requires histopathologic confirmation. They specify eight cognitive domains that may be impaired in AD: memory, language, perceptual skills, attention, constructive abilities, orientation, problem solving, and functional abilities. 